\title{
Sociocultural factors influencing maternal health outcomes in Nigeria
}

\author{
Onyejose, Kenneth N.; Ndep, Antor O.; Offiong, Dominic A.; Omang, Joseph A.; and Otu, Fidelis T. \\ Department of Public Health, Faculty of Allied Medical Sciences, University of Calabar, Calabar; Nigeria \\ DOI: $10.31364 /$ SCIRJ/v7.i11.2019.P1119728 \\ http://dx.doi.org/10.31364/SCIRJ/v7.i11.2019.P1119728
}

\begin{abstract}
Maternal health outcomes, just like other health indicators are influenced by sociocultural factors prevailing in the context where the population of interest exists. Human beings interact with their environment, both physical and sociocultural and these interactions influence their physical and mental wellbeing. Maternal mortality and morbidity is a marker of the status of health of the population. This review informed by recent development in maternal and newborn health was conducted to determine how the sociocultural factors have contributed to maternal health outcomes in Nigeria. It involved search of current and recent literature and identified twenty two (22) articles, the contents read and organized into themes - Gender and maternal health, sociocultural determinants and maternal health outcomes. The papers seek to provide answers on how factors within the physical and social environment have contributed to maternal health outcomes. Findings from the review revealed that social and cultural factors for example age, religion, traditional belief system, education, marital status, socioeconomic status and societal construction of gender are major determinants of maternal health outcomes in Nigeria. It recommended that for there to be any meaningful improvement on maternal health outcomes, it is incumbent that these factors are investigated further especially to the different context in which proposed interventions are to be implemented. It cautioned that it is important to consider the context as what might be a major determinant in some regions may actually not be seen as a serious factor in other parts of Nigeria.
\end{abstract}

Keywords: Sociocultural, maternal health, Nigeria

\section{Introduction}

Maternal health outcomes, just like other health indicators are influenced by sociocultural factors prevailing in the context where the population of interest exists. Human beings interact with their environment, both physical and sociocultural and these interactions influence their physical and mental wellbeing. Maternal mortality and morbidity is a marker of the status of health of the population. The "Poor understanding of the interplay of many antecedent factors, including sociocultural, economic and logistic factors, combined with an overwhelming poor health services delivery, is a basic challenge in several countries, particularly in rural settings where functional health care services are relatively scarce" (Azuh et al, 2017). Maternal mortality often is taken as a major indicator 
or marker of health of the population and of socioeconomic development of a given population. It is particularly high in most African countries particularly within sub-Saharan Africa. There have been tremendous efforts towards improving maternal and newborn health outcomes but despite the investment, not much has been achieved as the maternal and newborn mortality is still unacceptably high (Azuh et al, 2017). Babalola and Fatusi (2009) posited that "Africa has the highest burden of maternal mortality in the world and sub-Saharan Africa is largely responsible for the dismal maternal death figures for the region, contributing $66 \%$ of the maternal deaths for the region".

The past twenty years witnessed an improvement in terms access to and use of innovative sexual and reproductive health (SRH) services, however, there has been slowing down of progress in several countries and after years of investments, one can say it has been disappointing. Health analysts and other stakeholders have shown the potential impact that continuous inequities in health play in reducing progression in attaining national and global goals. Inequity in health can be defined as "inequalities in health deemed to be unfair or to stem from some form of injustice (WHO, 1996). The dimensions of being avoidable or unnecessary have often been added to this concept" (WHO, 1996). World Health Assembly (1996) "review of progress towards reducing inequities in coverage of key maternal, newborn, and child health interventions concluded that most countries examined: "have made gradual progress in reducing the coverage gap for key interventions since 1990 (WHO, 1996). The coverage gaps, however, are still very wide and the pace of decline needs to be more than doubled to make significant progress in the years between (2008) and 2015 to reach levels of coverage of these and other interventions needed for MDG 4 and 5 ".

Generally, each country trends of this inequality are consistent and only vary progressively and this has consequences for the tailoring of strategies (World Health Assembly, 1996). Also, exploration of differences in acceptance of current family planning methods established that affluent persons are accepting contraception at a much faster rate than the less affluent (Krug et al, 1999) widening the rich-poor gap in service utilization and corresponding advantages of reduced fertility. The existence of these rich- poor gaps in health status and utilization of health services is of interest to public health programs, political leaders, and civil society because these disparities are markers of injustice in society as well as indicators of the capacity of the public health system to meet the needs of all especially the most vulnerable ones.

There is enough evidence of the association between lack and weak reproductive health outcome (WHO, 2015). Greene and Merrick (2005) conducted "a thorough review of the social, financial and health consequences of key reproductive health indicators including maternal survival, early childbearing and unintended pregnancy. The report concluded that large family size was associated with increased risk of maternal mortality and less investment in children's education. Unwanted pregnancy was positively correlated with health risks of unsafe abortion. Short birth intervals were found to negatively influence child survival, and early pregnancy was 
associated with lifelong risk of morbidities. Researchers have also documented that large families are more likely to become poor and less likely to recover from poverty than smaller family households" (Greene and Merrick, 2005).

\section{Methodology}

The systematic review of literature on sociocultural determinants of maternal health outcomes in Nigeria focused on the sociocultural determinants contributed to the high number of maternal mortality and morbidity of women as a result of pregnancy. It involved an in-depth search of current and recent literature with inclusion and exclusion criteria for peer-reviewed journal articles and the results are organized into themes. The search was conducted in published articles in Google Scholar, CINAHL, Health Source and PubMed in September 2019. The keywords "maternal health outcomes", "Nigeria" and "sociocultural determinants" were used as selection criteria. Furthermore, journal articles published between 2000 and 2019 were included in the search criteria and articles written in other languages outside English were not included. Twenty two (22) articles met the selected criteria, and after review, were organized into the following themes: Gender and maternal health, sociocultural determinants and maternal health outcomes.

\section{Gender and Maternal mortality}

Nigeria just like other African nations is traditionally a patriarchal society whereby women and girls are relegated to the background and usually dominated and discriminated against from early childhood. In most settings, differences in gender are mostly noticeable with the female gender mostly getting minimal attention than their male counterpart. Chukuezi (2010) noted that "poorer access to medical services is compounded by social, cultural and economic factors including gender inequality in access to food, by burden of work and by special dietary requirements such as iron supplements. This is why many women and particularly rural women are often trapped in a cycle of ill-health exacerbated by child bearing and hard physical labor”.

Gender as a socially constructed phenomenon often produces unexpected health risks due to social roles and expectations that are linked to gender role occupancy (Jackson \& Williams, 2006). The gender perspective as discussed during the 1997 NGO symposium on Health for all women and men, "looks at how socially constructed roles and relationships have direct bearing on the health and wellbeing of both sexes" (Chukuezi, 2010). Haslegrave (1997) took a look at how "gender perspective helps identify the inequalities between women and men, which in the field of health can lead to both increased illness and death from preventable causes. A gender approach to health examines how gender differences determine access to benefits and the way in which technology; information, resources and healthcare are distributed. It provides the foundation for maximizing human resources in development because the result of equal access to resource benefits and opportunity to all will be a more enlightened educated, healthy and independent society". 
Gender constructs, which are a key component that influences the distribution of disease, are defined on the basis of the social and cultural norms and values of the people. Similarly, culture intersects with gender to stratify individuals within a given society into different classes or categories. These class differences are defined by education, income and occupational status, which in turn create room for opportunities, privilege and desirable resources. This means that whatever opportunities and threats that the people are exposed to within a given context are a function of the social and cultural definition of gender. For example, if a group of people defined by a particular gender (masculine) are more valued, they will have greater access to power and resources than the other group (feminine). These power and resources go a long way in determining ones health outcomes.

Firstly, females have lesser access to power and resources, thereby making them reliant on the males for their economic survival. As a result, males become gatekeepers for sex. Women's economic dependence on men, which includes their high poverty levels and lack of access to opportunities and resources, contributes to their vulnerability to HIV/AIDS and other health conditions (Whiteside et al, 2003). The basis for this is that men could threaten to withdraw their economic support if these women do not comply with their demands. It is an established fact that females earn far less than their male counterparts even when they have the same level of education. As a result, they are not adequately empowered to make decisions concerning their health. Secondly, females are most times not permitted to be partakers when it comes to decision making especially on issues that affect them, as women are relegated to mere spectator status in the legislative branch of governments.

Thirdly, until recently, education of the girl child was not given a top priority as they are often seen as objects of men that will be married sooner than later. Wives are seen as properties of their husbands and have no role other than the traditional care-giving and childbearing. Thus, training of the girl child was seen as wasteful. The trend has started changing but the effects that have transcended several generations still linger. In most parts of Africa, cultural practices and traditions bestow on a husband an exclusive right of ownership over his wife. As a result, she is under the full control of the man and does not have the power to own property or other resources, or even the capacity discuss on issues affecting their sexual life and determine when to get pregnant.

It is essential that efforts geared towards reduction maternal deaths and ill health as a matter of urgency treat the social and cultural issues that affect the health of women. It is therefore important that the low status of women within the communities, poor or limited access to and control of wealth, lower opportunities for education, limited access to nutritious foods and not involved in the making of decisions need to be seen as a moral burden and a call for action as no nation can achieve its full potentials without considering the role of women in nation building (Chukuezi, 2010). Socioeconomic status (SES) is one of the strongest determinants of health as it determines differential access to power, privilege, and desirable resources (Adler et al, 1995).

\section{Sociocultural factors and maternal health outcomes}


An observational study by Guerrier et al (2013) on maternal and neonatal mortality in Northern Nigeria found that "there was a greater burden of maternal death in the youngest age groups than other age groups. This may be due to the generally low age at marriage, a typical occurrence in rural northern Nigerian settings (Rai et al, 2012). The association between early childbearing, adverse pregnancy outcomes, and high maternal mortality has been established (Omar et al. 2012); (Rashed et al, 2011). Delaying pregnancy, education of women, and community-based interventions to implement family planning appear to be priorities in an attempt to reduce maternal mortality".

Poverty and malnutrition are major contributors to Maternal and child mortality in developing nations. Factors associated with these problems include, weak socio-economic status, poor health care delivery system and lack of utilization of healthcare delivery services (Ibeh, 2008). He noted that "monitoring maternal mortality is difficult due to poor reporting and lack of proper methods to measure actual death rates. Estimating the real figure is difficult as only $31 \%$ women deliver in health facilities" (Lindros \& Lukkainen, 2004). "The gap of maternal deaths between rich and poor countries is wide with $99 \%$ of these deaths occurring in the developing world. A study conducted by Olusegun et al (2012) on curbing maternal and child mortality: The Nigerian experience found that low socioeconomic development, weak health care system and low socio-cultural barriers to care utilization. They also identified some key interventions needed to addressing the problem as care during pregnancy, birth and postpartum supports".

Ononokpono and Odimegwu (2014) in their study of the determinants of Maternal Health Care Utilization in Nigeria found "that in addition to several individual factors, region of residence was significantly associated with facility delivery. Women who lived in Northern Nigeria were less likely to deliver in a health facility than those who resided in the Southern part of the country. Residence in communities with a high proportion of women who had secondary and higher education significantly increased the odds of facility delivery whereas ethnic diversity was negatively associated with health facility delivery. The study recommended that interventions aimed at promoting the use of health facility for childbirth should not only be implemented at the individual level but also tailored to the community level as interventions conceived without consideration for community context are likely to have limited impact. It also added that increasing women's education in disadvantaged communities and region-specific interventions that increase access to health facilities are likely to have far-reaching impacts in reducing maternal mortality”.

Lowe et al (2016) conducted an exploratory qualitative study in rural community in Gambia. The study found "that the division of labor between men and women in the household was such that women often engaged in non-remunerable field work with few economic resources, and their household duties during pregnancy were not alleviated by either their husbands or the other members of polygamous households. At the time of delivery, the decision to receive care by trained personnel was often beyond the women's control, resulting in birth-related complications. The study concluded that despite women's multiple roles in the household, their

WwW.scirj.org 
positions are quite unfavorable. The high maternal morbidity and mortality rate in The Gambia is related to practices associated with gender inequality".

Dapaah and Nachinaab (2019) in their study sought to identify the types of maternal healthcare services (MHCS) that pregnant women received during pregnancy, delivery and postpartum and the reasons for their use or no use of such services. The study showed "that some sociocultural factors such as age, religion, traditional belief system, education, and marital status influence women's use of MHCS in the Talensi District. In addition, factors such as women's National Health Insurance Scheme status, distance to health center, and attitude of health care professional determine their utilization of MHCS. Some of these reasons influence their choice of TBAs to the formal health sector. It recommended that women need to be educated on the need for them to utilize healthcare services during pregnancy, delivery and after child birth".

Yarney (2019) studied how knowledge on sociocultural factors associated with maternal mortality affect maternal health decisions in a rural community in Ghana. The study found "statistically significant relationship exists between all the socio-cultural factors studied (Traditional Birth Attendants (TBAs), religious beliefs and practices, herbal concoctions, and pregnancy and childbirthrelated taboos) and maternal health decisions ( $p=0.001$ for all the variables) with very strong associations between maternal health decisions and knowledge on pregnancy and childbirth related taboos, TBA patronage, and religious beliefs and practices. The study added that misconceptions on factors associated with maternal mortality deeply rooted in rural communities partly explain why maternal morbidity and mortality are persistent in Ghana. It concluded that meaningful and successful interventions can only be achieved if misconceptions on causes of maternal mortality especially in rural areas of the country are tackled through mass education of communities. This should be done consistently over a long period of time for sustained behavioral change".

Akokuwebe and Okafor (2015) examined the factors that brought about poor maternal health by critically identifying and discussing factors such as poverty, low level of education, inaccessibility of health care services, unbooked emergencies, and hypertensive disorder of pregnancy, obstructed labour, anemia, hemorrhage and infection. The "research informed by functionalist and political economy theories, argued that the present maternal health is incapable of ensuring sustainable transformation in Nigeria owing to massive corruption, misplacement of priority, neo-liberal policies of government, leading to social and economic dislocation of families and widespread poverty. It concluded by arguing that, for there to be real sustainable transformation of Nigeria, the issue of maternal health should be accorded priority through reducing maternal mortality rate by government and other stakeholders. This could be achieved through massive enlightenment, sustainable education, poverty reduction, and adequate provision and funding of healthcare facilities in Nigeria”. 
Ogu et al (2016) conducted a review which focused on the sociocultural influences that contribute to the high rate of maternal mortality in Nigeria. The paper "highlighted the need for key interventions to mitigate the impact of negative sociocultural practices and social inequality that decrease women's access to evidence-based reproductive health services that lead to high rate of maternal mortality. It recommended strategies to overcome identified negative sociocultural influences and ultimately galvanize efforts towards achieving sustainable development goals".

In some cultures, it is almost a taboo to give birth by Caesarian Section because it will be seen as a sign of laziness. As a result of this and some other reasons, women chose to deliver by going to the traditional birth attendants (TBAs).Although TBAs are not considered as SBAs, in 2004, the World Health Organization (WHO), the International Confederation of Midwives (ICM) and the International Federation of Gynecology and Obstetrics (FIGO) issued a joint statement encouraging countries to work with TBAs and ensure cooperation between TBAs, skilled attendants, and staff in referral facilities. This took into consideration that TBAs have a significant role to play to ensure improved maternal and newborn health outcomes. The improvements of access to skilled care during pregnancy, childbirth, and postpartum remains a priority strategy for improving maternal health (Miller and Smith, 2017). Most of these TBAs may not have the requisite skills in conducting deliveries for complicated cases thereby leading to death of mothers and their babies.

The need to specify roles for TBAs acknowledges their cultural and social acceptability and the important role that they play in supporting the health of women and newborns and linking women, families and communities to the formal health system (WHO, 2009). Also, the strategies to increase the use of SBAs where TBAs are providers of childbirth care have generally involved linking TBAs with formal health services, increasing partnerships or teamwork with TBAs, or finding new roles (Miller\& Smith, 2017). New roles for TBAs in the formal health system include encouraging and accompanying women to attend antenatal and postnatal care and have skilled care during birth, providing companionship to women during and after childbirth, as well as broader roles that they can play in community-level health education and community mobilization strategies to improve MNH (Miller and Smith, 2017). Strategies to increase partnerships with TBAs include developing collaborative relationships through opportunities for reciprocal sharing of traditional and professional knowledge between TBAs and SBAs, emphasizing such collaboration in in-service midwifery training (WHO, 2009) as well as including TBAs in community level networks and as links in referral chains for skilled care (Ronsmans \& Gunawan, et al, 2001).

Similarly, in Nigeria, people often seek care from drug vendors also known as Patent and Proprietary Medicine Vendors (PPMVs) for common but potentially deadly illnesses, (Goodman \& Brieger, 2007). Although PPMVs are not always recognized as front-line health workers, they provide the first and the main point of care in many communities. In some settings, training drug vendors to 
provide high-quality basic services, such as the treatment of common childhood illnesses and malaria, may offer a cost-effective way of delivering community-based health programs (Awor \& Wamani et al. 2014). PPMVs are defined as "a person without formal training in pharmacy who sells orthodox pharmaceutical products on a retail basis for profit" (Brieger \& Osamor et al. 2004). They were established as a category of retailer by the Nigerian Ministry of Health to provide a source of medicine in communities with limited access to essential health commodities (Barnes \& Chandani et al. 2008). It is important to note that most residents in the rural communities would rather patronize these TBAs and PPMVs mainly because of cost and ignorance.

\section{Conclusion}

From the review, it was clear that some sociocultural factors such as age, religion, traditional belief system, education, marital status, socioeconomic status and societal construction of gender are major determinants of maternal health outcomes in Nigeria. For there to be any meaningful improvement on maternal health outcomes, it is incumbent that these factors are studied in detail with particular attention to the different context in which proposed interventions are to be implemented. It is a known fact that these factors determine the outcomes of maternal health. However, it is important to consider the context as what might be a major determinant in the Northern part of Nigeria might not be considered so strong a factor in the Southern region. So an analysis of the local environment might be useful in determining some of these differences that could appear not too serious on the surface but might turn out to be the silver bullet to ensuring lasting success in one's intervention.

The government and other stakeholders can actually provide an enabling environment in form of legislations to mitigate some of the harmful effects of some of these sociocultural factors driving the level of maternal deaths to unacceptably high levels. In some cases, regulating the activities and changing roles for TBAs can help reduce mothers dying in the hands of this unskilled group of people. It is possible that TBAs can work collaboratively with SBAs in health facilities towards addressing maternal mortality and possibly also, the TBAs could be encouraged to provide escort services of pregnant women from the communities to the health facilities. Some of the proceeds from the delivery can be shared at an agreed rate to cover for the cost of transportation and other incidentals as this will encourage them to continue in the collaborative work with SBAs.

Finally, it is critical that the government invest heavily in the area of maternal and child health as that is one of the major ways to ensure that there is improvement in maternal and newborn health outcome. The government should not just rely on donor funds and waiting for foreigners to drive development in this key area of our development. The government at all levels should drive the process and take the lead role. Donors can offer additional support, which will be appreciated if available. It is hoped that if the above are done, that we are on a sure part to success towards reducing maternal mortality in Nigeria. 


\section{References}

1. Adler, N.E., Boyce, W. T., Chesney, M. A., Folkman, S., \& Syme, S. L. (1993). "Socioeconomic Inequalities in Health: No Easy Solution”. Journal of the $\quad$ American Medical Association, 269, 3140-3145.

2. Akokuwebe ME and Okafor EE (2010). Maternal Health and the Implications for $\quad$ Sustainable Transformation in Nigeria, Research on Humanities and Social Sciences Vol.5, No.6, 2015.

3. Awor P, Wamani H, Tylleskar T, Jagoe G, Peterson S. Increased access to care and appropriateness of treatment at private sector drug shops with integrated management of malaria, pneumonia and diarrhoea: a quasiexperimental study in Uganda. PLoS ONE. 2014;9(12):e115440. doi: http:// dx.doi.org/10.1371/journal.pone.0115440 PMID: 25541703

4. Azuh DE, Azuh AE, Iweala EJ, Adeloye D, Akanbi M, Mordi RC (2017). Factors influencing maternal mortality among rural communities in southwestern Nigeria, ～DOI https://doi.org/10.2147/IJWH.S120184

5. Babalola S, and Fatusi A (2009). Determinants of use of maternal health services in Nigeria: looking beyond individual and household factors. BMC Pregnancy Childbirth.;9(43):1-13.

6. Barnes J, Chandani T, Feeley R (2008) Nigeria Private Sector Health Assessment. $\quad$ Bethesda, MD: Private Sector Partnerships-One project, Abt Associates Inc.

7. Brieger WR, Osamor PE, Salami KK, Oladepo O, Otusanya SA (2004) Interactions between patent medicine vendors and customers in urban and rural Nigeria. Health Policy Plan 19: 177-182. [PubMed

8. Chukuezi, C. (2010).Socio-cultural Factors Associated with Maternal Mortality in Nigeria. Research Journal of Social Sciences, 1(5): 22-26, 2010

9. Dapaah JM and Nachinaab JO (2019). Sociocultural Determinants of the Utilization of Maternal Health Care Services in the Tallensi District in The Upper East Region of Ghana. Advances in Public Health Volume 2019, Article ID 5487293, $11 \quad$ pages.

10. Goodman C, Brieger W, Unwin A, Mills A, Meek S, Greer G. Medicine sellers and malaria treatment in sub-Saharan Africa: what do they do and how can their practice be improved? Am J Trop Med Hyg. 2007 Dec;77(6) Suppl:203-18. PMID: 18165494

11. Guerrier G, Oluyide B, Keramarou M, and Grais R, (2013). High maternal and neonatal mortality rates in northern Nigeria: an 8-month observational study, International Journal of Women's Health 
12. Greene M, Merrick T. Poverty reduction: does reproductive health matter? Washington, DC: The World Bank; 2005 (HNP Discussion Paper).

13. Haslegrave, M., 1997. The role of NGOs in promoting a gender approach to healthcare: http//www.un.org/womenwatch/daw/csw/role_ngo. htm.

14. Ibeh CC (2008). Is poor maternal mortality index in Nigeria a problem of care utilization? A case study of Anambra State. Afr. J. Reprod. Health, 12(1): 132- 140.

15. Jackson, P.B. \& Williams, D.R. (2006). The intersection of race, gender, and SES: $\quad$ Health paradoxes. Schulz \& Mullings (2006): Gender, race, class and health. California: Wiley.

16. Krug EG, Dahlberg LL, Mercy JA, Zwi AB, Lozano R, editors. World report on violence $\quad$ and health. Geneva: World Health Organization; 2002. 3. Heise L, Ellsberg M, Gottemoeller M. Ending violence against women. Population Reports, Series L: $\quad$ Issues in World Health 1999; 11:1-43.

17. Lindros A, Lukkainen A (2004). Antenatal care and maternal mortality in Nigeria. Public Health Programme - exchange to Nigeria. Retrieved on September 19, 2019 from www.antenatal-Nigeria.pdf

18. Lowe M, Chen D and Huang S (2016) Social and Cultural Factors Affecting Maternal Health in Rural Gambia: An Exploratory Qualitative Study. ～LOSONEDOI:10.1371/journal.pone.0163653

19. Miller KJ and Smith RS, (2017). Establishing partnership with traditional birth attendants $\quad$ for improved maternal and newborn health: a review of factors influencing implementation.

20. Ogu RN, Agholor KN and Okonofua FE (2016). Engendering the Attainment of the SDG-3 in Africa: Overcoming the Socio Cultural Factors Contributing to Maternal Mortality, African Journal of Reproductive Health September 2016 (Special Edition); 20(3): 62

21. Olusegun1 OL, Ibe, RT and Ikorok MM, (2012). Curbing maternal and child mortality: The Nigerian experience. International Journal of Nursing and Midwifery Vol. 4(3), pp. 33-39,

22. Omar K, Hasim S, Muhammad NA, Jaffar A, Hashim SM, Siraj HH. (2012). Adolescent pregnancy outcomes and risk factors in Malaysia. Int J Gynaecol Obstet. 010;111(3):220-223.

23. Ononokpono DN and Odimegwu CO. (2014). Determinants of Maternal Health Care Utilization in Nigeria: a multilevel approach. Pan African Medical Journal. 17(Supp 1):2.

24. Rai RK, Singh PK, Singh L. Utilization of maternal health care services among married adolescent women: insights from the Nigeria Demographic and Health Survey, $\quad$ 2008. Women Health Issues. 2012;22(4): e407-e414. 
25. Rasheed S, Abdelmonem A, Amin M. Adolescent pregnancy in Upper Egypt. Int J 24.

26. Ronsmans C, Endang A, Gunawan S, et al. Evaluation of a comprehensive home-based midwifery programme in South Kalimantan, Indonesia. Trop Med Int Health. $\quad$ 2001;6(10):799-810.

27. Whiteside, A., Hickley, A., Ngcobo, N. \& Tomlinson, J. (2003). What is driving the HIV/AIDS epidemic in Swaziland, and what more can we do about it? (NERCHA): Swaziland and (HEARD): Durban.

28. World Health Assembly. Prevention of violence:a priority health issue. Geneva: WHA; May 25, 1996 (Sixth plenary meeting. Committee B, fourth report, 3rd edition).

29. World Health Organization. Working with individuals, families and communities to improve maternal and newborn health. Geneva: Department of Making Pregnancy Safer; 2010. p. 2010.

30. Yarney L (2019). Does knowledge on socio-cultural factors associated with maternal mortality affect maternal health decisions? A cross-sectional study of the Greater Accra region of Ghana BMC Pregnancy and Childbirth (2019) 19:47 https://doi.org/10.1186/s12884-019-2197-7

WwW.scirj.org (C) 2019, Scientific Research Journal 